\title{
Segurança alimentare a alta dos preços dos alimentos: oportunidades e desafios
}

\author{
José G raziano da Silva e Lucas Tavares²
}

\begin{abstract}
Este artigo se propõe a analisar como a alta dos preços dos alimentos e a recessão podem afetar a segurança alimentar e, a partir da identificação das causas do aumento de preços, propor políticas que aproveitem as oportunidades que ela encerra para avançar no combate à fome e à pobreza. Embora a alta dos preços dos alimentos seja uma ameaça real à sobrevivência de famílias muito pobres, ela também é uma oportunidade para estimular a inserção produtiva de milhões de pequenos produtores que vivem na pobreza extrema em áreas rurais da A mérica Latina. Não se trata de privilegiar um grupo sobre 0 outro, mas agir simultaneamente em duas frentes para proteger os vulneráveis e permitir o desenvolvimento das famílias pobres nas áreas rurais.
\end{abstract}

Palavra-chave: preço dos alimentos, agricultura familiar, distribuição de renda, pobreza.

\section{Food security and rising food prices: opportunities and challenges}

This article proposes an analysis of how the rise in food prices and recession may affect food security and, from the identification of the factors that cause the rise of food prices, propose public policies that take advantage of the opportunities they offer in advancing in the fight against hunger and against poverty. Even though high food prices are a real menace to the survival of very poor families, they are also an opportunity to stimulate the productive insertion of millions of small-scale farmers living in extreme poverty in rural areas around Latin America. It is not about privileging one group over another, but to act simultaneously in both fronts to protect the vulnerable and foster the development of poor rural families.

Keyword: food prices, family farming, income distribution, poverty.

\section{Seguridad alimentaria y el alza de los precios de los alimentos: oportunidades y desafíos}

El artículo se propone analizar como el alza de los precios de los alimentosy la recesión pueden afectar la seguridad alimentaria y, a partir de la identificación de las causas del alza de los precios, proponer políticas públicas que aprovechen las oportunidades que el alza trae para avanzar en el combate al hambre y a la pobreza. Aunque el alza de los precios de los alimentos sea una

${ }^{1}$ Representante Regional da FAO para América Latina e Caribe e Instituto de Economia - IE (UNICAMP).

${ }^{2}$ Escritório Regional da FAO para América Latina e Caribe. 
amenaza real a la supervivencia de las familias muy pobres, ella también representa una oportunidad para estimular la inserción productiva de millones de pequeños productores que viven en la pobreza extrema en zonas rurales de América Latina. No se trata de privilegiar un grupo sobre el otro, sino de actuar simultáneamente en los dos frentes para proteger a los vulnerables y permitir el desarrollo de las familias pobres en zonas rurales.

Palabras-llave: costo de los alimentos, agricultura familiar, distribuición de la renta, pobreza.

\section{Introdução}

A conjuntura econômica internacional atual causa preocupações para o desenvolvimento dos países. A pós cinco anos de crescimento, surge agora a ameaça de uma recessão originalmente causada pela crise imobiliária norte-americana, mas que rapidamente atingiu proporções glo bais. Análises dos fundamentos macroeconômicos da América Latina em geral e do Brasil em particular indicam que ambos estão mais preparados para enfrentar crises externas. E é possível que uma recessão norte-americana não cause, necessariamente, uma retração igual nas outras economias por causa do peso cada vez maior de outros países, como China e Índia, na demanda mundial de commodities.

No entanto, a volatilidade dos mercados e as incertezas sobre se o pior da crise imobiliária já foi ou não superada mantém as dúvidas em relação ao panorama econômico futuro. A situação preocupa porque, como na maioria das crises, o preço nem sempre é pago de acordo com a responsabilidade de cada um. Embora a atual crise econômica tenha origem num fato específico em um país desenvolvido, as populações mais pobres dos países não desenvolvidos correm o risco de estar entre os maiores prejudicados.

À ameaça da recessão, soma-se outra que já tem um impacto direto especialmente na segurança alimentar e nutricional de milhões de pessoas em todo o mundo: a alta dos preços dos alimentos.

Apesar disso, o atual cenário não apresenta só ameaças; também existem oportunidades que podem e devem ser aproveitadas. Mesmo numa conjuntura econômica repleta de incertezas como a atual, é possível avançar na garantia da segurança alimentar e nutricional, em particular nos países produtores de alimentos. Isso porque apesar da ameaça da recessão norte-americana, a demanda por cereais continua alta e empurrando os preços para cima. Este aumento pode ser usado para estimular a produção da agricultura familiar. E políticas públicas devidamente orientadas podem não só proteger os pequenos produtores, mas também permitir uma maior inserção deles no mercado.

O presente artigo se propõe a analisar, a partir do estudo de fontes secundárias de informação, as oportunidades e desafios que o atual cenário econômico - de alta dos preços dos alimentos representa para a segurança alimentar.

O conceito de segurança alimentar é amplo e engloba as dimensões da disponibilidade, acesso, estabilidade e utilização. 0 foco deste artigo está orientado ao impacto mais imediato que a conjuntura descrita nos parágrafos anteriores pode causar e, portanto, focará nas dimensões de disponibilidade e acesso.

\section{Recessão, alta dos preços e segurança alimentar}

\section{Recessão}

Erradicar a fome e a pobreza é o primeiro O bjetivo de D esenvolvimento do Milênio ${ }^{1}$. Informe da Organização das Nações Unidas sobre o avanço em direção aos Objetivos de Desenvolvimento do Milênio afirma que, entre 1990 e 2004, 270 milhões

\footnotetext{
${ }^{1}$ O s oito O bjetivos de D esenvolvimento do Milênio foram adotados em 2000 por todos os países membros da O rganização das Nações Unidas (O NU). 0 primeiro objetivo é erradicar a pobreza e a extrema e a fome. D uas metas foram fixadas para esse objetivo: reduzir pela metade, até 2015, a proporção de pessoas vivendo em pobreza extrema e a proporção das pessoas com fome (ano base 1990). Três indicadores são usados para verificar o cumprimento da primeira Meta do Milênio (pobreza): percentual da população que vive com menos de US\$1 por dia, a razão da insuficiência de renda (em quanto à renda média dos pobres está abaixo da linha de pobreza) e participação do quinto mais pobre no consumo nacional. Em relação à medição da segunda Meta do Milênio (fome), dois indicadores são utilizados: prevalência de crianças menores de cinco anos com peso muito baixo para sua idade - dois ou mais desvios padrão da mediana da distribuição de referência - e proporção da população com um consumo de energia alimentar menor que o mínimo.
} 
de pessoas superaram a pobreza extrema [1].

O crescimento econômico é hoje condição indispensável para a redução da pobreza e da fome, especialmente nos chamados Países de Baixa Renda e D éficit Alimentar ${ }^{2}$. Empurradas pelo crescimento econômico da China e Índia ${ }^{3}$, as maiores reduções na pobreza extrema foram no leste e no sudeste asiático, onde entre 1990 e 2004 ela caiu, respectivamente, de $33 \%$ para $9 \%$ e de $20,8 \%$ para 6,8\%. Na América Latina e Caribe, a redução foi bem mais modesta: a pobreza extrema diminuiu de $10,3 \%$ para $8,7 \%$.

A América Latina consegue melhores resultados a partir de 2003, quando começa uma fase de crescimento econômico que não se via na região desde a década de 70: entre 2003 e 2007 a economia regional cresceu em média quase $5 \%$ ao ano. Foram anos de expansão que fizeram disparar uma espiral benigna em diferentes indicadores sociais. D esde 2002, o número total de indigentes na América Latina caiu de 221 milhões para 190 milhões de pessoas. A proporção de indigentes, que havia caído de $22,5 \%$ para $19,4 \%$ entre 1990 e 2002, diminuiu de $19,4 \%$ para $12,7 \%$ entre 2002 e 2007 [2].

Das 69 milhões de pessoas que, segundo estimativa da Cepal, viviam em situação de indigência em 2007, 36,1 milhões de pessoas viviam em áreas rurais e 35,2 milhões em áreas urbanas ${ }^{4}$. No entanto, proporcionalmente, o problema é mais grave no campo: 29,4\% das pessoas que viviam em áreas rurais eram indigentes enquanto nas áreas urbanas essa proporção era de apenas 8,6 \% [2].

Apesar disso, mantido este ritmo, a primeira Meta do Milênio de redução da pobreza extrema seria alcançada. Mas os avanços na redução da pobreza não têm sido acompanhados por uma melhor distribuição de renda que permita às pessoas mais pobres ter renda suficiente para comprar 0 necessário para uma vida saudável e digna. Entre 1990 e 2004, a proporção da renda dos 20\% mais pobres da população mundial na renda total caiu de 4,6\% para 3,9\%. Na América Latina e Caribe, que já era a região mais desigual do mundo segundo este indicador, a participação do quinto mais pobre da população caiu um pouco mais, passando de $2,8 \%$ para 2,7\% [1]. 0 aumento da desigualdade indica que há espaço para resultados melhores se ao objetivo de crescimento econômico se agregar a necessidade de uma melhor distribuição dos seus frutos.

Em relação à redução da fome no mundo, os avanços conseguidos até agora são insuficientes para alcançar a Segunda Meta do Milênio (reduzir pela metade a proporção de famintos no mundo entre 1990 e 2015) e 0 compromisso ainda mais ambicioso assumido, em 1996, na Cúpula Mundial da Alimentação (reduzir pela metade o número total de famintos entre 1990 e 2015). A diferença entre essas duas metas é expressiva: equivale a quase 168 milhões de pessoas no mundo em desenvolvimento e mais de 11 milhões a nível regional.

Vários fatores são importantes para que haja um avanço mais rápido em direção à redução da subnutrição, dos quais citamos três:

1. Maior compromisso político dos Governos e Estados, ancorados em marcos legais que garantam 0 direito à alimentação e promovam a segurança alimentar e nutricional.

2. Políticas públicas integradas e coordenadas entre si que enfrentem os diferentes lados do problema - necessidade de dar ajuda emergencial, apoiar inserção produtiva etc.

3. Investimentos maiores e mais eficientes.

Se medirmos a fome pela proporção de pessoas que ingerem alimentos cujo valor calórico é

\footnotetext{
${ }^{2}$ A FAO considera 82 países como sendo países de baixa renda e com déficit de alimentos (LIFDC, na sigla em inglês). Na América Latina e Caribe são quatro países: Equador, Haiti, Honduras e Nicarágua. A lista completa está disponível em: http:/ / www.fao.org/ countryprofiles/ lifdc.asp?lang=es\&. A FAO também acompanha a segurança alimentar atual dos países. Em fevereiro de 2008, a organização considerava que 36 países enfrentavam crises alimentares (causadas por motivos que podem incluir desde conflitos internos até fenômenos climáticos que prejudicam safras como secas e inundações) e precisavam de ajuda externa para alimentar a sua população. São 21 países na África, nove na Ásia, quatro na América Latina (Bolívia, Haiti, Nicarágua e República D ominicana) e dois na Europa.
} 
cronicamente inferior ao mínimo necessário, 0 percentual de subnutridos no mundo caiu de $20 \%$ a $17 \%$ entre os períodos de 1990-1992 e 2002-2004. A redução anual média está em 1,3\%, abaixo dos 2,73\% necessários para atingir a meta. Na América Latina e Caribe, a redução foi de $13 \%$ a $10 \%$. Reduzimos a fome mais rapidamente ( $2,2 \%$ ao ano), mas ainda não chegamos à velocidade necessária. Isso significa que, para cumprir a meta de 2015, teremos que conseguir resultados melhores. Os avanços na região são díspares: há países que já atingiram a meta (Chile, Cuba, Guiana, Peru e Uruguai) ou alcançarão a meta mantido o ritmo atual (Brasil, Haiti, Jamaica e Suriname) e outros que se distanciaram da meta nos últimos anos (Argentina, G uatemala, República D ominicana, Venezuela) ${ }^{5}$.

A necessidade de se avançar com mais rapidez também se evidencia ao analisar os dados referentes à diminuição da proporção de crianças menores de cinco anos de idade com peso muito baixo para sua idade, o outro indicador utilizado para medir a segunda Meta do Milênio. O percentual caiu de 33\% para $27 \%$, no âmbito mundial, e de $11 \%$ para $7 \%$, na América Latina e Caribe. Segundo a ONU, isso significa que extrapolaríamos a meta em 2015 em 30 milhões de crianças [1]. Traduzindo: são 30 milhões de crianças que não conseguirão desenvolver todo seu potencial porque não receberam alimentação adequada nos seus primeiros anos de vida.

Entre os exemplos positivos na redução da pobreza extrema e da fome, vale destacar a contribuição brasileira. 0 Brasil já atingiu a primeira meta (pobreza) e pode alcançar a segunda (fome) se mantiver o atual ritmo. Entre 2003 e 2005, 2,7 milhões de pessoas superaram a pobreza extrema no país [3] 6 , melhor resultado desde a queda de 4,3 milhões registrada entre 1993 e 1995.

A continuação do crescimento econômico, no
Brasil e no mundo, facilitaria o aumento dos investimentos na área social e, portanto, o combate à pobreza e à fome. Uma recessão pode ter o efeito oposto. E, da mesma forma que os benefícios do crescimento nem sempre são repartidos de forma igual, como mostra o aumento da desigualdade nos últimos anos, os custos da recessão também são absorvidos de forma desigual, com a população pobre dos países em desenvolvimento pagando um preço proporcionalmente mais alto. Apenas para lembrar um exemplo, o Brasil, assim como toda a região, viveu um período forte de ajustes na década de 80 cujo custo foi pago, principalmente, pelos mais pobres [4].

Esforços fiscais que permitam uma política anticíclica, na qual os investimentos nas áreas sociais pelo menos se mantenham em épocas de menor crescimento, é uma forma de proteger as camadas mais vulneráveis. É importante ressaltar que esses investimentos sociais não se resumem às políticas compensatórias ou assistenciais. Para que os mais vulneráveis possam superar as dificuldades por meio do próprio esforço é preciso desenvolver políticas que promovam câmbios estruturais, daí a validade de iniciativas como as transferências condicionadas de renda, com ênfase nas condicionalidades e na integração com políticas de capacitação, inserção trabalhista etc.

D e modo geral, pode-se dizer que a recessão ameaça a segurança alimentar e não aumenta as oportunidades dos mais pobres. Ainda assim, os governos podem e devem adotar políticas para enfrentar a situação, conforme indicado anteriormente.

\section{Alta dos preços}

À ameaça de recessão, soma-se outro problema: a alta dos preços dos alimentos ${ }^{7}$. Os

\footnotetext{
${ }^{3}$ D esde 1989, a China cresce mais de 9,5\% ao ano. Na Índia, o resultado é um pouco mais modesto: mais próximo aos 7\% anuais (estimativa feita a partir do Panorama Econômico Mundial de outubro de 2007 do Fundo Monetário Internacional (FMI)).

${ }^{4}$ Em relação à pobreza (incluída a indigência), a Cepal estima que ela afetava a 35,1\% da população em 2007, ou 190 milhões de pessoas.

${ }^{5}$ O s dados utilizados para essa categorização são os dados preliminares disponíveis até 2004. D esde então, pode ter havido mudanças. No caso da Venezuela, por exemplo, entre 2004 e 2006 há uma redução significativa na indigência [2] e, ainda que a FAO não tenha dados relativos aos índices de subnutrição nesse período é possível que eles tenham uma correlação.
} 
números dão uma idéia da magnitude do problema.

A FAO projeta que os Países de Baixa Renda e Importadores de Alimentos comprarão em 2007/ 2008 uma quantidade de cereais $2 \%$ menor que no período anterior, mas pagarão 35\% a mais [5]. Em todo o mundo, 82 países integram este grupo. $\mathrm{Na}$ América Latina e Caribe, são quatro: Equador, Haiti, Honduras e Nicarágua.

A alta dos preços dos alimentos é quase generalizada. 0 preço internacional do trigo em janeiro de 2008, por exemplo, estava 83\% acima do preço no mesmo mês do ano anterior. 0 milho e arroz também subiram, porém em menor proporção. Estima-se que para cada $1 \%$ de aumento nos preços dos alimentos, o gasto no consumo dos países em desenvolvimento sobe 0,75\% [6]. Outro efeito igualmente importante para a segurança alimentar é que, frente a alimentos mais caros, a população pobre procura alternativas de menor qualidade nutritiva, geralmente pobres em micronutrientes [7].

A alta dos alimentos afeta com mais gravidade, principalmente, os países cujos gastos com comida respondem pela maior parte do orçamento familiar. Por exemplo, em países como Armênia, Botsuana, Geórgia, Laos, Madagascar, Moldóvia, Ruanda, Tajiquistão, Ucrânia e Zâmbia o gasto com comida representa mais de $60 \%$ do consumo total ${ }^{8}$. $\mathrm{Na}$ América Latina e Caribe, 0 gasto é de $20 \%$ a $30 \%$ em países como Argentina, Brasil, Chile e Colômbia.

No entanto, é importante lembrar que a alta dos preços pode ter impactos diferentes nas famílias. Se a alta dos preços será positiva ou negativa para uma família em particular depende se ela é produtora ou compradora líquida de alimentos. Uma família produtora de alimentos pode se beneficiar da alta ainda que viva em um país que, em geral, será prejudicado [8]. Para entender melhor esta relação, a FAO está iniciando uma pesquisa para identificar os determinantes da alta de preços na América Latina e Caribe e o seu impacto na segurança alimentar das famílias.

Ao contrário do impacto da recessão na segurança alimentar, que em geral sempre será negativo e exige políticas públicas que busquem enfrentar a diminuição do poder de compra, a alta dos preços traz ameaças, mas também oportunidades.

\section{Causas para a alta dos preços}

Vários fatores influenciam atualmente 0 aumento do preço dos alimentos. Do lado da demanda, cresceu o consumo humano, uso de cereais para a produção de ração animal e também há a pressão dos agrocombustíveis, principalmente no milho, matéria prima para o etanol produzido pelos Estados Unidos. Pela oferta, os principais motivos são os diversos fenômenos climáticos que prejudicaram safras recentes ${ }^{9}$, a alta do preço do petróleo que encarece 0 custo do transporte e a especulação decorrente dos baixos estoques.

A primeira coisa a fazer é reconhecer que a oferta de alimentos aumentou, mas a demanda cresceu ainda mais. Ou seja, nos últimos anos consumimos mais do que produzimos. A produção de cereais projetada pela FAO para 2007 é de 2,102 bilhões de toneladas [9]. Uma safra recorde, mas, ainda assim, insuficiente para atender à maior demanda: 2,120 bilhões de toneladas.

O crescimento econômico registrado nos últimos anos estimulou o consumo de alimentos

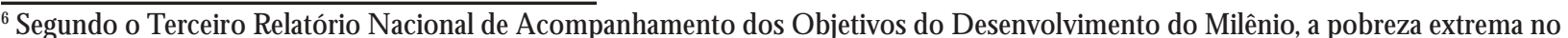
Brasil é caracterizada por renda inferior a $1 \frac{1}{4}$ de salário mínimo per capita e a pobreza por uma renda inferior a $1 \frac{1}{2}$ salário mínimo per capita.

${ }^{7}$ Alta que não afeta apenas os alimentos, mas os preços das commodities em geral, incluídas as agrícolas, as minerais e o petróleo.

${ }^{8}$ D ados se referem a anos diversos a partir de 1990 e estão disponíveis no FAO STAT, banco de dados da FAO: http:/ / www.fao.org/ faostat/ foodsecurity/ Files/ ShareOfFood_en.xls

${ }^{9}$ Para citar apenas dois exemplos: a Nicarágua ainda se recupera da passagem do Furacão Félix e, em fevereiro de 2008, a Bolívia enfrentava grandes inundações causadas pelo fenômeno climático conhecido como La Niña.

${ }^{10}$ Veja, por exemplo, matéria "Blame it on biofuels", publicada na edição de 20 a 27 de agosto de 2007 da revista N ewsweek: http:/ / www.msnbc.msn.com/ id/ 20226750/ site/ newsweek/
} 
mais protéicos. Ou seja, além de comer mais, as pessoas também estão comendo melhor. Entre 1985 e 2007, por exemplo, os chineses aumentaram 0 consumo de carne em $150 \%$ : de 20 a 50 quilos por ano. Considerando que até oito quilos de grãos são necessários para produzir um quilo de carne e que a população do país já superou 1,3 bilhão, é fácil entender a pressão dessa demanda na alta dos preços dos alimentos. $\mathrm{O}$ aumento do consumo de carne não acontece somente na China. A FAO cita também mudanças significativas no padrão de consumo de alimentos no Brasil e na Índia [10].

0 crescimento econômico, portanto, influencia a alta do preço dos alimentos de duas maneiras: 0 consumo direto de cereais pelas pessoas ea utilização de cereais para produção de ração para animais. Este último fator é resultado de um maior consumo de alimentos mais protéicos, que ocorre sempre que há um aumento de renda das populações mais pobres.

Ainda no que diz respeito à demanda, há um crescimento do uso não agrícola de cereais que se explica, basicamente, pelos agrocombustíveis. A possibilidade de plantar combustível ganhou 0 mundo. E trouxe com ela três expectativas: oferecer uma alternativa viável ou complemento ao combustível fóssil; reduzir a emissão de gases de efeito estufa; e promover o desenvolvimento de países pobres com capacidade para produzir agrocombustíveis.

Se os agrocombustíveis cumprirão ou não as três expectativas ainda é algo incerto, mas há oportunidades claras em relação à segurança alimentar que veremos mais à frente. No entanto, hoje, embora não dê para quantificar o peso exato dos agrocombustíveis na alta do preço dos alimentos, ele existe ${ }^{10}$. 0 que 0 impulsiona é, principalmente, a antecipação pelo mercado do impacto das novas metas de produção e consumo de etanol nos Estados Unidos, que é o maior produtor mundial de milho, insumo muito utilizado na cadeia de produção animal.

No discurso sobre o Estado da União em maio de 2007, o presidente G eorge W. Bush elevou a meta de produção de combustíveis alternativos de 45 bilhões de litros em 2012 para 132 bilhões de litros em 2017. Se cumprida, a meta significa substituir $15 \%$ do consumo de gasolina nos EUA ${ }^{11}$. Apenas para fins de comparação, segundo o Ministério da Agricultura, Pecuária e Abastecimento, a produção de etanol no Brasil deverá crescer mais de $100 \%$ entre a safra 2006/ 2007 e 2017/ 2018, subindo de 17,6 bilhões de litros para 41,6 bilhões [11].

Ou seja, os Estados Unidos triplicaram uma meta que já era considerada ousada. Apesar disso, vale lembrar que desde 2007 os preços de trigo e soja aumentaram consideravelmente mais que os preços do milho, matéria prima do etanol norteamericano. No Chicago Board of Trade, o preço futuro do trigo subiu cerca de $160 \%$ de janeiro de 2007 a março de 2008 e o preço futuro da soja aumentou aproximadamente $120 \%$ e o do milho pouco mais de $40 \%$. Isso pode significar que a alta dos preços está sendo puxada mais pela demanda por alimentos que de biocombustíveis. 0 trigo é fundamental para a dieta da população chinesa e de outros países e a soja é utilizada para diversos fins, inclusive a produção de ração animal na cadeia produtiva de carnes.

Do lado da oferta, também há fatores pressionando os preços. Fenômenos climáticos prejudicaram as colheitas nos últimos anos. A produção disparou entre 2002 e 2004, subindo de pouco menos de 1,85 bilhões de toneladas para mais de 2,05 bilhões, mas caiu nos dois anos seguintes para aproximadamente dois bilhões [5].

Em 2005/2006, o mundo produziu pouco mais do que consumiu, mas desde então a oferta tem sido menor que a demanda. Este é o dado fundamental para se entender o atual aumento do preço dos alimentos. Produção menor que 0 consumo obriga a utilizar estoques acumulados anteriormente e que mantinham os preços baixos. Em conseqüência, a FAO projeta que os estoques de cereais ao final de 2008 atinjam o menor nível em mais de duas décadas, caindo $5 \%$ para 405 milhões de toneladas (equivalente a menos de $20 \%$ do consumo anual) [5].

\footnotetext{
${ }^{11}$ http:/ / www.whitehouse.gov/ stateoftheunion/ 2007/ initiatives/ energy.html
} 
É preciso destacar que os preços agrícolas não são determinados pela intersecção entre a oferta e a demanda correntes, tal como se ensina nas escolas de economia de tradição ortodoxa. Na verdade, a função de oferta agrícola não é contínua, correspondendo a um tempo determinado do ano (época da safra) enquanto a demanda está presente ao longo de todo o ano. Portanto, o preço dos principais produtos agrícolas é determinado pelos fluxos de liberação dos estoques em função da demanda corrente, dando um caráter ainda mais "imperfeito" a esses mercados, até porque as variáveis que afetam o ritmo do escoamento da produção (taxa de juros, expectativa de preços no atacado, disponibilidade de armazéns, volume de estoques presente, oferta esperada etc.) são completamente distintas daquelas que afetam a intenção de plantio (preços ao produtor, demanda corrente, disponibilidade de credito, sementes, terras e outros meios de produção etc.).

O u seja, existe sempre um componente importante de especulação ${ }^{12}$ na determinação dos preços agrícolas. $\mathrm{O}$ que pagamos hoje por um alimento na realidade é resultado de uma definição que ocorreu no passado, baseada na especulação sobre a provável oferta e demanda futura, os resultados do próprio plantio e a demanda efetiva do presente.

Nos momentos de retração, a função de demanda dos produtos agrícolas declina porque 0 consumo da população diminui. Como muitos produtos agrícolas têm demanda inelástica em relação a preços e renda, a demanda corrente sempre cai menos que a oferta subseqüente. Isso acontece porque a queda na demanda presente desestimula os produtores por ocasião do novo plantio, criando uma expectativa negativa para a oferta subseqüente. Desse modo, considerando-se apenas os fluxos da demanda corrente e a oferta esperada, o diagnóstico comum tende a identificar o problema como "falta de produto" quando a causa primária é a queda de demanda.
Nos momentos de expansão, o mecanismo é simétrico: a oferta, embora responda rapidamente aos preços, é sempre defasada (pelo tempo de produção dos bens agrícolas) em relação à expansão da demanda. 0 resultado é que, num primeiro momento, os preços sobem, criando estímulos adicionais ao crescimento da produção futura. Ao mesmo tempo, os preços elevados em relação à renda criam pressões inflacionárias, desestimulando maiores elevações do consumo. Aqui também 0 diagnóstico comum é de "insuficiência da oferta", quando na realidade trata-se de uma questão de disponibilidade de estoques.

Vale a pena assinalar que esses diagnósticos de "insuficiência de oferta", quando na realidade trata-se de uma queda na demanda corrente ou de manipulação especulativa dos estoques durante 0 período de defasagem (ou seja, de entressafra), sempre terminam por beneficiar os intermediários e não os produtores [12].

A atual conjuntura acentua 0 problema do desequilíbrio entre a oferta e a demanda. Com os estoques em baixa, a instabilidade do mercado financeiro e a queda do dólar, os fundos de commodities voltaram a ser uma boa opção de investimento. Quer dizer, existe também um fator especulativo na sua acepção corriqueira e negativa.

0 último fator relevante que estimula 0 aumento dos preços dos alimentos é a alta do preço do petróleo, que tem um impacto direto no preço ao encarecer o transporte. E distribuir os produtos deve continuar caro no futuro próximo. Em 19 de fevereiro, o barril rompeu a barreira histórica dos US\$100 [13].

\section{Enfrentando a ameaça}

A recessão e a alta dos preços dos alimentos apontam para um cenário preocupante para as pessoas mais pobres, principalmente de países

\footnotetext{
${ }_{12}$ Especulação na acepção do Dicionário Houaiss: "estudo teórico, baseado predominantemente no raciocínio abstrato; análise, investigação, disquisição". Neste sentido, a especulação é um exercício econômico fundamental para tentar prever situações futuras e não deve ser confundida com o uso negativo e corriqueiro da palavra, relacionada à tentativa de obter lucro sobre oscilações do mercado.

${ }^{13}$ E quiparando assim a tarifa zero que já valia para a importação de trigo argentino.
} 
importadores líquidos de alimentos e em emergência alimentar.

No entanto, existem medidas que os governos podem tomar para proteger os mais vulneráveis da recessão, entre elas, aproveitar as oportunidades oferecidas pela alta dos preços. Esta oportunidade existe para regiões produtoras de alimentos, como a América Latina, e, em particular, para países como o Brasil.

É essencial agirnessas duas frentes para garantir a segurança alimentar da população, especialmente na América Latina, região onde a pobreza extrema é dividida entre as áreas urbanas e rurais.

\section{Protegendo os mais vulneráveis}

A população urbana tende a ser compradora líquida de alimentos e, portanto, pode ser mais afetada pela alta dos preços. A situação é especialmente grave em países nos quais a população dedica maior parte da sua renda à compra de comida. A melhor maneira de combater esse problema é por meio da geração de mais empregos com melhor remuneração. Dado o crescimento econômico registrado nos últimos anos, essa é uma alternativa viável, e que vem acontecendo em vários países, como China, Índia e Brasil.

No caso brasileiro, isso é evidente, por exemplo, em São Paulo. A pesar da alta da cesta básica de 17,9\% entre dezembro de 2006 e dezembro de 2007, o comprometimento do salário mínimo com a compra da cesta básica pelo trabalhador paulistano no ano passado foi de 51,95\%, a menor proporção necessária desde 1971 [14].

Há várias ações que os governos podem implantar para proteger os mais pobres do aumento dos preços. Entre o fim de 2007 e o início de 2008, governos latino-americanos lançavam mão de instrumentos como redução de tarifas de importação, aumento de subsídios alimentares e a proibição ou taxação da exportação de produtos alimentares para enfrentar a alta dos preços.
Para citar alguns exemplos, o Peru reduziu as tarifas de importação do trigo, farinha de trigo e milho, enquanto que na Bolívia e no Equador os governos subsidiam a produção do pão. $O$ governo boliviano também autorizou o Exército a produzir pão em algumas fábricas para atender à população mais vulnerável. No Brasil, em janeiro de 2008, discutia-se a possibilidade de reduzir de $10 \%$ para zero a tarifa de importação de trigo ${ }^{13}$. 0 México reduziu a zero as tarifas de importação de milho, açúcar, leite e outros produtos, de acordo com 0 Tratado de Livre Comércio da América do Norte (TLCAN) [9, 5]. E a Venezuela optou por congelar os preços.

A decisão venezuelana vale um comentário à parte. Estipular um teto de preço é uma medida extrema que, para funcionar, precisa ser de curto prazo para evitar risco de desabastecimento. 0 êxito depende também da informação disponível. No caso venezuelano, o setor privado sabe que o estoque de alimentos do governo está baixo, mas o governo não sabe 0 nível das reservas privadas. Isso tolhe seu poder de iniciativa e facilita o desabastecimento.

Em outras partes do mundo, são usados mecanismos similares aos já citados. 0 Egito aumentou o subsídio alimentar, enquanto Marrocos, Indonésia e Coréia do Sul reduziram a tarifa de importação de cereais. Zâmbia e Etiópia suspenderam a exportação de diversos cereais, a África do Sul planeja aumentar a ajuda social a famílias pobres e Zimbábue subsidia a venda do milho, trigo e sorgo importado. A China está taxando a exportação de cereais e, ao mesmo tempo, anunciou que vai aumentar o preço mínimo de compra de cereais e os subsídios à agricultura para estimular a plantação de grãos em 2008 [9, 5].

\section{Aproveitando as oportunidades apresentadas pela alta dos preços}

Enquanto a maioria da população tende a ser compradora líquida, sua parte agrícola, pelo menos, tem 0 potencial para ser produtora de alimentos e se beneficiar da alta dos preços.

\footnotetext{
${ }^{14} \mathrm{O}$ aumento da oferta do continente americano serviu, inclusive, para compensar quedas de produção em outras regiões do mundo.
} 
Embora exista uma defasagem natural entre oferta e demanda na agricultura devido ao tempo que decorre entre o plantio e a colheita, é certo que a oferta será estimulada a satisfazer a demanda. Isso já está acontecendo, como demonstra a colheita recorde (embora ainda insuficiente) de cereais, projetada para 2008.

Entre 2006 e 2007, a produção de cereais aumentou 4,6\%, o equivalente a 92 milhões de toneladas [5]. Desse total, 77 milhões de toneladas vieram da América do Norte, região que aumentou sua produção em $20 \%$, e quase 20 milhões de toneladas da América Latina e Caribe, cuja produção subiu $15 \%^{14}$. É justamente nessas regiões que estão os maiores produtores e consumidores de etanol de cana de açúcar e milho e é provável que o aumento na demanda por agrocombustíveis esteja estimulando a oferta. Isso mostra que a produção de agrocombustíveis não precisa ser feita às custas da segurança alimentar.

Os agrocombustíveis podem beneficiar a segurança alimentar de várias maneiras. Em primeiro lugar, é preciso esclarecer que o etanol pode ser produzido a partir de diversas fontes e com diferentes impactos na segurança alimentar. $O$ etanol produzido a partir da cana de açúcar, principalmente, no Brasil tem um impacto muito menor no preço dos alimentos que o etanol produzido a partir do milho nos Estados Unidos ${ }^{15}$. Portanto, a venda de etanol brasileiro feito de cana de açúcar aos Estados Unidos $^{16}$ poderia reduzir a pressão sobre 0 preço do milho ${ }^{17}$, principalmente na América Central e México, onde é parte essencial da dieta ${ }^{18}$.

Incluir a agricultura familiar na produção de biocombustíveis também pode promover a segurança alimentar. É importante lembrar que, no Brasil, é a pobreza que causa a insegurança alimentar e não a falta de produção: falta poder aquisitivo para comprar os alimentos disponíveis [15]. A mesma realidade se repete na maioria dos outros países da
América Latina e Caribe. Apoiar a participação da agricultura familiar na produção de biocombustíveis pode aumentar a renda dos pequenos produtores rurais. No Brasil, segundo o Ministério do D esenvolvimento Agrário, mais de 100 mil agricultores familiares já participavam da cadeia de produção de biodiesel em novembro de 2007 [16]. Um dos estímulos à produção é o Selo Social, que, por meio de incentivos fiscais, favorece a compra de matéria prima da agricultura familiar pelas empresas produtoras de biodiesel.

Portanto, além da convivência conjunta ser possível, os agrocombustíveis também podem contribuir para a segurança alimentar garantindo melhores preços para a agricultura familiar. Esse é o desafio: aproveitar a alta dos alimentos em benefício dos pequenos.

D e modo geral, o agronegócio já está reagindo ao crescimento dos preços - como comprova o aumento da produção de cereais nas Américas em 2007 - e certamente será o maior beneficiário da alta. "O agronegócio brasileiro vendeu a clientes estrangeiros US\$ 58,4 bilhões em mercadorias no ano passado. 0 valor corresponde a mais de um terço de tudo o que o Brasil exportou em 2007. No balanço anual das transações do agronegócio, 0 país obteve superávit de quase $\mathrm{R} \$$ 50 bilhões - maior, portanto, que o saldo de R\$ 40 bilhões obtidos na balança de todo o comércio no período" [17].

O paradoxo no campo latino-americano é que a pobreza extrema rural persiste, apesar do boom agrícola, e ainda que tenha diminuído um pouco em alguns países, entre eles o Brasil. Ela afeta 36,1 milhões pessoas na região, justamente as mais prejudicadas pela queda constante dos preços de alimentos registrada nas últimas três décadas. Uma queda que foi apenas parcialmente recuperada pelo movimento recente de alta de preços [18] e pode ajudar a explicar a migração de áreas rurais a urbanas:

\footnotetext{
${ }^{15}$ D eixamos de lado aqui outras questões, como a eficiência energética: 0 etanol de milho consome quase tanta energia quanto produz, enquanto o etanol da cana de açúcar gera oito vezes mais energia que a consumida na sua produção.

${ }^{16}$ A venda de etanol importado nos Estados Unidos é, hoje, praticamente inviável por causa de barreiras tarifárias.

${ }^{17} \mathrm{O}$ aumento do preço do milho tem um efeito cascata, encarecendo também a produção de carnes.

${ }^{18}$ Mais do que isso: 0 milho faz parte da cultura e história do povo do México e da América Central. Segundo o Popol V uh, livro sagrado dos Mayas, os deuses primeiro tentar povoar o mundo com homens feitos de madeira e, ao fracassar, fizeram-no a partir do milho.
} 
entre 1970 e 2005 a população rural brasileira, por exemplo, caiu de 45 milhões para 31 milhões.

A questão é como fazer com que oportunidade que se abre com a alta dos preços beneficie também a agricultura familiar. A tualmente, a agricultura familiar tem uma produtividade baixa na região, mas, ao mesmo tempo, um peso fundamental na geração de ocupação e renda. No Brasil, por exemplo, ela é responsável por $77 \%$ dos ocupados rurais, mas participa com apenas $28 \%$ da produção setorial, aponta um estudo conjunto realizado entre o Escritório Regional da FAO para América Latina e Caribe e o Banco Interamericano de D esenvolvimento (BID ) em $2007^{19}$ [19]. A brecha de produtividade é grande, o que significa que se podem conseguir melhoras significativas com relativamente poucos investimentos.

Para que a oportunidade seja aproveitada é necessário somar esforços ao já tradicional apoio à oferta - crédito, capacitação e assistência técnica - e investir numa nova família de políticas agrícolas que assegurem uma fatia adicional da demanda e dos mercados à agricultura familiar. Embora a alta dos preços tenha diversas causas, algumas das quais insustentáveis no largo prazo (como é o caso da especulação financeira), a demanda por biocombustíveis e por alimentos deve continuar. Portanto, há espaço para aproveitar a demanda e criar novos mercados.

Existem vários exemplos de políticas públicas que garantem o acesso ao mercado como, por exemplo, o Programa de Aquisição de Alimentos brasileiro e as compras da agricultura familiar associadas a demandas institucionais, caso da bem sucedida iniciativa do Programa Nacional de Alimentação E scolar. A tualmente, cerca de 35\% dos alimentos da cesta básica distribuída pela Companhia Nacional de Abastecimento (Conab), são oriundos da agricultura familiar [20]. D eve-se trabalhar para aumentar essa proporção. O utras alternativas podem e estão sendo implantadas com 0 mesmo sentido. A já citada produção do biodiesel é uma dessas alternativas, que também fortalece a criação de capital social incentivando o cooperativismo e sistemas de parceria entre os pequenos produtores.

O terreno está aberto para passos mais ousados. $O$ estudo conjunto realizado pela FAO e 0 BID mediu o impacto da abertura comercial na agricultura familiar e chegou à seguinte conclusão: ele é praticamente nulo. Em geral, os agricultores familiares não são afetados negativamente pela concorrência externa, mas tampouco conseguem aproveitar as vantagens da liberalização de mercados porque se ressentem da ausência de políticas públicas que apóiem essa inserção.

Existe uma lição a ser aprendida: é preciso promover uma reestruturação das políticas de desenvolvimento direcionadas à agricultura familiar. Nas últimas décadas descuidou-se da produção para priorizar políticas sociais. Antes, na sua maioria, políticas meramente assistenciais. E, mais recentemente, políticas que buscam criar as condições para transformações estruturais através de transferências condicionadas de renda. No Brasil, é o caso do Bolsa Família. Não se trata de descartar uma em proveito de outra - escolher entre a política social ou de inserção produtiva. Na realidade, a intervenção estatal tem que se dar pelas duas vias: ajudar famílias vulneráveis a superar fases difíceis e, ao mesmo tempo, incentivá-las a produzir mais, expandir mercados e consolidar o terreno conquistado.

Isso aponta para uma realidade às vezes esquecida: fome e extrema pobreza não são fenômenos iguais. Essa distinção é importante porque reforça a necessidade de políticas públicas

\footnotetext{
${ }^{19} \mathrm{O}$ estudo abrange seis países: Brasil, Chile, Colômbia, Equador, México e Nicarágua, país onde a agricultura familiar participa com $67 \%$ do valor total da produção agrícola. A menor participação está no Chile (participação de $27 \%$ no valor e de 57\% na geração de emprego setorial).

${ }^{20}$ Em dezembro de 2007, o Escritório Regional da FAO organizou em conjunto com a CEPAL, PMA e PNUD, o Segundo Seminário Internacional sobre Transferências Condicionadas, Erradicação da Fome da D esnutrição Crônica Infantil. Mais informações sobre 0 tema estão disponíveis em: http:/ / www.rlc.fao.org/ es/ prioridades/ seguridad/ ingreso2/

${ }^{21}$ Índice calculado pelo Escritório Regional da FAO a partir da oferta de energia alimentar per capita e o requerimento energético médio mínimo per capita. Refere-se à média de dados de 2002 a 2004.
} 
diferentes, mas combinadas, de curto e longo prazo, para enfrentar esses dois problemas. A transferência condicionada de renda, por exemplo, é um instrumento útil e já usado por 16 países latinoamericanos $[21]^{20}$, cujo impacto potencial aumenta quando ela faz parte de um conjunto integrado de políticas públicas de combate à fome e à pobreza.

Colocando a questão de modo simples, a transferência dá um alívio imediato às famílias em situações vulneráveis ao mesmo tempo em que investe na superação da pobreza no longo prazo através da exigência das condicionalidades, normalmente relacionadas à saúde e à educação, cujo cumprimento facilitaria a inserção futura no mercado de trabalho. No entanto, para ser efetiva, é preciso que as famílias beneficiadas tenham acesso a serviços públicos de qualidade.

Também é cada vez mais clara a necessidade de superar essa dualidade entre 0 curto e o longo prazo oferecendo saídas sustentáveis da exclusão, garantindo a inserção produtiva dos adultos de hoje e não só das gerações futuras. Se não fizermos isso, corremos o risco de que uma política de inclusão social termine como mais uma forma de assistencialismo.

NaAmérica Latina e no Brasil é especialmente importante apoiar a agricultura familiar como forma de garantir a segurança alimentar. Nesse sentido, a alta dos preços de alimentos apresenta uma oportunidade que, se bem estimulada e aproveitada, pode ser um atalho ao desenvolvimento e ajudar a abastecer os mercados internos, salvando direta e indiretamente milhões de pessoas da fome e da insegurança alimentar.

E não se trata de exportar menos. A tualmente a América Latina e Caribe já têm um superávit de $31 \%$ na oferta de energia alimentar. Ou seja, somando o que a região produz e importa de alimentos, subtraindo o que se exporta e é consumido para outros fins, ainda assim, há alimento de sobra para alimentar a toda sua população. No Brasil a abundância é ainda maior, atingindo $41 \%{ }^{21}$.

\section{Políticas internacionais}

Entre as políticas que os governos podem lançar mão para minimizar ou evitar o impacto da alta de preços nas pessoas mais vulneráveis estão a redução de tarifas de importação. No entanto, nem essa, nem qualquer uma das alternativas mencionadas, podem ser aplicadas automaticamente em qualquer país.

Tome-se o caso brasileiro. A redução de tarifas de importação pode ser importante para garantir a oferta de um ou outro produto determinado, sempre que a capacidade de produção nacional não seja suficiente no momento. Mas é importante que essa ação seja acompanhada do estímulo à produção nacional, preferencialmente, dos pequenos produtores.

É preciso atuar nas duas frentes e, quando possível, utilizando políticas complementares com benefícios mútuos: o excedente da maior produção da agricultura familiar abastece o mercado local e aumenta a disponibilidade de produtos. Mas se 0 mercado é imperfeito, essa maior disponibilidade pode não se traduzir automaticamente em preços menores. É preciso uma intervenção do Estado também aí, principalmente, no que diz respeito à compilação e à distribuição da informação relacionada ao meio agrícola: preços de referência, estoques existentes, produção projetada, enfim, dados que orientem o mercado na formação de preços e também evite que a ação especulativa mencionada antes fique com os ganhos que deveriam beneficiar tanto os produtores quanto os consumidores.

Também é preciso destacar que a simples redução ou eliminação de tarifas pode ser prejudicial para a produção agrícola no longo prazo. Não se trata de ser a favor ou contra a liberalização comercial, mas de implantar as políticas corretas para minimizar os efeitos negativos e aumentar os benefícios. Isso não se faz com uma proteção cega a todo um setor, mas através de ações que, em um determinado horizonte, permitam que o setor enfrente a competição externa ou se adapte para atuar em novos mercados. 
Finalmente, é preciso lembrar que, sendo a alta dos preços dos alimentos um fenômeno mundial, também são necessárias ações mundiais para enfrentá-la. Uma das maiores dificuldades para estimular a pequena produção agrícola nos países em desenvolvimento e pobres são os subsídios agrícolas nos países desenvolvidos. E, aqui, é importante separar 0 apoio à produção interna do apoio à exportação. É neste segundo que se concentra 0 problema e onde os subsídios geram distorções de preços que tornam, em alguns casos, inviável a ampliação da produção.

A alta dos preços agrícolas abre espaço para uma significativa redução dos subsídios em geral e até mesmo a completa eliminação dos subsídios à exportação. As negociações comerciais podem ter um impacto significativo na alta dos preços dos alimentos: a eliminação dos subsídios agrícolas é, possivelmente, um dos maiores estímulos que a agricultura familiar dos países em desenvolvimento poderia receber.

\section{Conclusão}

Este artigo buscou mostrar como a alta dos preços dos alimentos e a recessão podem afetar a segurança alimentar e, a partir da identificação das causas do aumento de preços, propor políticas públicas que aproveitem as oportunidades que ela encerra para avançar o combate à fome e à pobreza.

Observou-se que o crescimento econômico recente tem sido o principal motor da redução da pobreza e da fome no mundo. Ainda que os avanços tenham sido limitados por uma piora na distribuição de renda, 0 crescimento permitiu que milhões de pessoas passassem a se alimentar de maneira nutricionalmente mais adequada, consumindo mais proteína animal. Dado o anterior, uma recessão reduziria 0 ritmo de avanço no combate à pobreza e à fome e, muito provavelmente, os investimentos sociais.

A alta dos preços dos alimentos pode agravar esta situação, reduzindo o poder de compra, principalmente, dos pobres urbanos e dos países de baixa renda e com déficit de alimentos. Esses países devem pagar este ano 35\% a mais que em 2007 para comprar uma quantidade de alimentos $2 \%$ menor.

Partiu-se então para a identificação das causas da alta de preços. Do lado da demanda, as principais razões são: 0 aumento do consumo humano possibilitado pelo já citado crescimento econômico e 0 uso de cereais para a produção de ração animal - já que as pessoas estão ingerindo mais carnes, além da nova pressão dos agrocombustíveis. Pela oferta, os principais fatores são os fenômenos climáticos que prejudicaram diversas safras, a alta do preço do petróleo e a especulação devido aos baixos estoques e queda do valor do dólar.

Notou-se também que embora a alta dos preços seja uma ameaça aos pobres urbanos, que devem ser protegidos por meio da ação do Estado, ela também apresenta uma oportunidade para salvar milhões de pessoas da pobreza extrema nas áreas rurais. Isso porque os preços altos estimulam a produção e, tudo indica, a demanda continuará crescente no futuro próximo. Frisou-se ainda que a lógica de competição entre agrocombustíveis e segurança alimentar não precisa existir e que a primeira pode, efetivamente, aumentar a segunda.

Procurou-se também mostrar a importância de aproveitar a oportunidade representada pela alta dos alimentos e sugeriu-se que, ao lado do tradicional apoio à oferta, as políticas públicas invistam em garantir mercados aos produtos da agricultura familiar, por exemplo, mediante programas de compras institucionais.

Em síntese, fica evidente que a alta dos preços dos alimentos preocupa e precisamos proteger os mais vulneráveis garantindo seu acesso a uma alimentação em qualidade e quantidade suficiente. Ao mesmo tempo, precisamos aproveitar a oportunidade representada pela alta dos preços e incentivar a produção da agricultura familiar para consumo próprio e para comercialização. Esse estímulo permitiria ampliar a produtividade e a renda das famílias engajadas na agricultura familiar, aumentar a oferta de alimentos e ajudar a frear a alta dos preços. 


\section{Referências Bibliográficas}

[1] O rganização das Nações Unidas. The Millenium Development Goals Report. Nova York: Nações Unidas; 2007. D isponível em: http:/ / www.un.org/ millenniumgoals/ pdf/ mdg2007.pdf

[2] Comissão Econômica para América Latina e Caribe. Panorama Social da América Latina. Santiago: Nações Unidas; 2007. Disponível em: http:/ / www.cepal.org/ cgi-bin/ getProd.asp?xml=/ publicaciones/ xml/ 5/ 30305/ P30305.xml\&xsl=/ dds/ tpl/ p9f.xsl\&base=/ tpl/ top-bottom.xsl

[3] Instituto de Pesquisa Econômica Aplicada. O bjetivos de D esenvolvimento do Milênio: relatório nacional de acompanhamento. Brasília: IPEA; 2007. Disponível em: http:/ / www.ipea.gov.br/ sites/ 000/ 2/ download/ TerceiroRelatorioNacionalO D M.pdf

[4] Tokman VE. Una voz en el camino. Empleo y equidad en América Latina: 40 años de búsqueda. Santiago: Fondo de Cultura Econômica; 2004.

[5] Organização das Nações Unidas para Agricultura e Alimentação. Crop Prospects and Food Situation no1 2008 fev. Roma: FAO; 2008. Disponível em: ftp:/ / ftp.fao.org/ docrep/ fao/ 010/ ah881e/ ah881e00.pdf

[6] Regmi A, D eepak MS, Seale Jr L, Bernstein J. Cross-country analysis of food consumption patterns. In: Regmi A (ed.) Changing structure of global food consumption and trade. Washington DC: United States Department of Agriculture Economic Research Service; 2001.

[7] Von Braum J. Food Policy Report: The World Food Situation: New Driving Forces and Required Actions. Washington, D.C: International Food Policy Research Institute; dez 2007. D isponível em: http:/ / www.ifpri.org/ pubs/ fpr/ pr18.pdf

[8] O rtega J, Rivera R. D eterminantes mundiales del aumento y volatilidad en los precios de los alimentos y sus efectos en la seguridad alimentaria. Santiago: Escritório Regional da FAO para América Latina e Caribe; D ocumento inédito.
[9] O rganização das Nações Unidas para Agricultura e Alimentação. Crop Prospects and Food Situation no6 dez 2007. Roma: FAO; Roma. Disponível em: ftp:/ / ftp.fao.org/ docrep/ fao/ 010/ ah877e/ ah877e00.pdf

[10] Diouf J. Talking points para entrevista coletiva do diretor-geral da FAO em 2007 dez 17. Roma: FAO; 2007. Disponível em: http:/ / www.fao.org/ newsroom/common/ ecg/1000733/ en/ facts99.pdf

[11] Ministério da Agricultura, Pecuária e do Abastecimento. Resumo executivo das Projeções do agronegócio mundial e do Brasil de 2006/2007 a 2017/ 2018. Brasília: MAPA; 2008. Disponível em: http:/ / www.agricultura.gov.br/ images/ MAPA/ arquivos_portal/proj_agro.pdf

[12] Graziano da Silva JF. A nova dinâmica da agricultura brasileira. 2a. ed. Campinas: Unicamp; 1999.

[13] Folha de S. Paulo. Preço do petróleo fecha acima dos US\$100 pela $1^{\mathrm{a}}$ vez na história. São Paulo: Folha de S. Paulo; 2008 fev 19. Disponível em:http:// www1.folha.uol.com.br/ folha/ dinheiro/ ult91u373960.shtml

[14] D epartamento Intersindical de Estatística e Estudos Socioeconômicos (2007). Nota à imprensa: em 2007, cesta básica tem forte alta. D IEESE: São Paulo; 2008 jan 7. Disponível em: http:// www.dieese.org.br/ rel/ rac/ racjan08.pdf

[15] Hoffmann R. Segurança Alimentar e Produção de Etanol no Brasil. Campinas: Revista Segurança Alimentar e Nutricional; 2006 13(2). D isponível em: http:// www.unicamp.br/ nepa/ arquivo_san/ Producao de Etanol.pdf

[16] Ministério do Desenvolvimento Agrário. Biodiesel conta com 100 mil agricultores familiares. Brasília: MDA; 2007 dez 27. Disponível em: http:/ / www.mda.gov.br/ portal/ index/ show/ index/ cod/ 134/ codInterno/ 15512

[17] FO LHA DE S. PAULO. Alimento na balança. Editorial. São Paulo: Folha de S. Paulo; 2008 fev 13. 
Disponível em: http:/ / www1.folha.uol.com.br/ fsp/ opiniao/ fz1302200801.htm

[18] The Economist. The end of cheap food. Londres: The Economist; $2007 \mathrm{dez} 8$.

[19] Soto F, Rodriguez M, Falconi C. Políticas para la agricultura familiar en América Latina y el Caribe - Resumen Ejecutivo. Escritório Regional da FAO para América Latina e Caribe/ BID: Santiago; 2007. Disponível em: http:/ / www.rlc.fao.org/ es/ desarrollo/ fao-bid/ pdf/ politicasafresu.pdf

[20] Companhia Nacional de Abastecimento. Informações sobre Agricultura Familiar. Conab: Brasília. D isponível em: http:/ / www.conab.gov.br/ c o n abweb/ agriculturaFamiliar/ agricultura_familiar_3.html

[21] Ramachandran M. Apresentação em representação do Programa Mundial de Alimentos (PMA) no Segundo Seminário Internacional sobre Transferências condicionadas, erradicação da fome e desnutrição infantil. Santiago: PMA; 2007 dez.
Disponível em: http:/ / www.rlc.fao.org/ es/ prioridades/ seguridad/ingreso 2/ pdf/ mackPMA.ppt

\section{Autores}

José G raziano da Silva - Representante Regional da FAO para América Latina e Caribe, professor titular licenciado do Instituto de Economia da Unicamp e ex-ministro Extraordinário de Segurança Alimentare Combate à Fome (2003) do Governo do Presidente Luiz Inácio Lula da Silva.

Lucas Tavares - Jornalista e mestre em Políticas Públicas e Governo pela FLACSO-Chile. Atualmente, trabalha como Consultor em Comunicação do Escritório Regional da FAO para América Latina e Caribe.

Correspondência: Email: lucas.tavares@ fao.org

Este texto é baseado em entrevistas concedidas e artigos publicados sobre o tema em meios brasileiros e latinoamericanos.

Recebido em 18/03/ 2008

Aceito em: 03/ 05/ 2008 